\title{
Aortic replacement in the setting of bicuspid aortic valve: How big? How much?
}

\author{
Thoralf M. Sundt, MD
}

Despite more than a decade of intense investigation, controversy persists regarding appropriate triggers for aortic replacement in the setting of bicuspid aortic valve. The difficulty is that the data are inescapably imperfect. Although we can count individuals with bicuspid valve who suffer dissection, we have an insufficient understanding of the true denominator of individuals at risk to calculate the probability of dissection for an individual patient. In addition, our own decision-making process is subject to "denominator neglect" or focus on the fact of the occurrence of the event rather than on the risk of the occurrence. Furthermore, the data are inherently incomplete given the asymmetric nature of outcomes information. Specifically, although we can see those who did or did not dissect among the patients not undergoing surgery, the converse is not true; the tragedy of prophylactic surgery is that one cannot distinguish those who have benefited through prevention of dissection from those who paid the price of surgery but in whom dissection would never have occurred. Finally, we have data for only some of the critical determinants of dissection. Structural failure occurs when stresses exceed strengths. Aortic diameter gives us some insight into stress but we have little information on the material strength of the aorta. Early indications that patients undergoing aortic valve replacement for bicuspid valve had a significant risk of aortic dissection were followed by laboratory data showing histologic, biochemical, and mechanical abnormalities supporting an aggressive approach to resection; however, more recent clinical studies call this into question. (J Thorac Cardiovasc Surg 2015;149:S6-9)

There remains controversy surrounding the appropriate criteria for intervention on the ascending aorta in the presence of a bicuspid aortic valve (BAV). Indeed, rather than cooling down, the controversy seems to be heating up. Starting with early autopsy studies demonstrating overrepresentation of individuals with this valvular phenotype among those affected by this aortic catastrophe, ${ }^{1}$ interest has grown as aortic surgery has developed as a subspecialty and the results of aortic intervention have improved. With recognition of the catastrophic nature of acute dissection, focus has turned to the role of prophylactic aortic replacement. Despite multidisciplinary guidelines and consensus statements ${ }^{2,3}$ and a sizable body of literature regarding the histology, biochemistry, and even genetics of bicuspid aortopathy, each year we seem to see more questions than answers. How, then, can decision making remain so difficult?

We strive to make evidence-based rather than anecdotedriven decisions. Unfortunately, however, the data concerning this question, like much of the data in medicine, are

From the Division of Cardiac Surgery, Massachusetts General Hospital, Harvard Medical School, Boston, Mass.

Disclosures: Author has nothing to disclose with regard to commercial support.

Read at The American Association for Thoracic Surgery Aortic Symposium, New York, New York, April 24-25, 2014.

Received for publication May 18, 2014; accepted for publication July 23, 2014; available ahead of print Sept 11, 2014.

Address for reprints: Thoralf M. Sundt, MD, Division of Cardiac Surgery, Massachusetts General Hospital, Edward D. Churchill Professor of Surgery, Harvard Medical School, 55 Fruit St, Boston, MA 02114 (E-mail: tsundt@partners.org).

$0022-5223 / \$ 36.00$

Copyright (c) 2015 by The American Association for Thoracic Surgery

http://dx.doi.org/10.1016/j.jtcvs.2014.07.069 fundamentally imperfect. This inconvenient truth has a profound impact on our decision-making process. In medicine, as in other complex endeavors, evidence may be used to make the decision or, much more commonly, to add nuance to a plan or even support a decision already made. The mode of decision making is much more a reflection of the quality of the data than of the quality of the decision maker. True evidenced-based decision making demands unambiguous data. As the quality of the data become less secure, we inch our way along the spectrum (Figure 1) away from evidence-based decision making and toward decisionbased evidence making. ${ }^{4}$ What is most important is to recognize the potential pitfalls that underlie our decisions. The case of BAV aortopathy is a case in point.

The imperfect nature of the data concerning bicuspid aortopathy push us toward the right on the spectrum of decision making illustrated in Figure 1. They suffer from at least 3 fundamental problems: insufficient understanding of the denominator to calculate risk, the asymmetric nature of outcomes information, and absence of data inputs for some of the critical variables.

\section{THE NUMERATOR OR DENOMINATOR PROBLEM}

In medicine generally, and particularly in surgery, clinicians reside in the numerator. We only see the individuals who come to our medical attention for one reason or another, most often with some complication of their condition. Accordingly, our data sets are fundamentally flawed by inclusion bias. Without the denominator, which includes the individuals who don't seek help, we cannot calculate risk with a frequentist statistical approach. Bayesian analytic methods are more helpful but less 


\section{Abbreviations and Acronyms \\ AVR $=$ aortic valve replacement \\ $\mathrm{BAV}=$ bicuspid aortic valve \\ $\mathrm{TAV}=$ tricuspid aortic valve}

familiar. In addition, our own decision-making process is subject to what is termed in decision science denominator neglect, or focus on the fact of the occurrence of the event rather than on the risk. ${ }^{5}$

How does this apply to bicuspid aortopathy? Although we are secure in the oft-reproduced observation that the risk of aortic catastrophe is quite significant at 6-cm diameter, and the resultant recommendation that intervention be undertaken at $5.5 \mathrm{~cm}$, it is also clear that many dissections occur below this diameter cutoff. ${ }^{6}$ Unfortunately, the vast majority of the population exhibit aortic diameter below this cutoff value, so the actual risk to an individual —at least on the basis of diameter alone-must be quite low. The critical question is whether the actual risk is lower than the risk associated with intervention.

\section{ASYMMETRIC INFORMATION}

The second fundamental problem is that outcome data are inherently and inescapably asymmetric. The universe of the information we would require to make a truly evidence-based decision is depicted in Figure 2. Unfortunately, some of these data are unknowable. We have a reasonable assessment of those individuals who have not undergone aortic replacement but yet have dissection develop. Although we may miss noting a few out-ofhospital deaths, we can expect to capture within population databases the majority of such individuals. Our information concerning patients who have not undergone aortic replacement and never have any aortic complications, however, is far from complete, as noted previously in the discussion of the numerator versus denominator problem. There have been a few efforts at population-based studies, although even these are flawed because of less than universal screening.

The relevant data points regarding those who have undergone aortic intervention are, however, frankly unknowable. It is impossible to know who would and would not have had dissection develop had they not undergone aortic replacement. The tragedy of prophylactic surgery is that one cannot distinguish those who have benefited through prevention of dissection and those who paid the price of surgery but in whom dissection would never have occurred.

\section{CRITICAL VARIABLES}

The third problem is that we have data for only some of the critical variables. Aortic dissection represents a structural failure of the aorta. Structural failure occurs

\section{Evidence-based decision making... or}

decision-based evidence making?

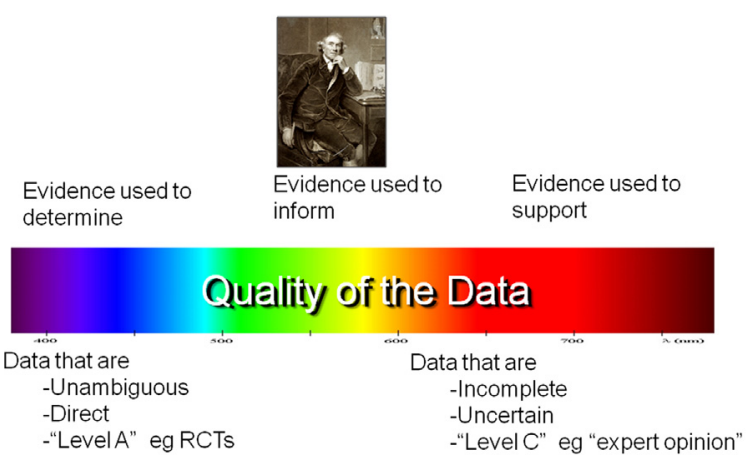

FIGURE 1. The spectrum of modalities of data use in decision making. $R C T s$, Randomized, controlled trials.

when stresses exceed strengths. The clinical observation is that larger aneurysms appear more prone to rupture than small ones. The explanation for this observation has commonly relied on Laplace's law and the increase in wall tension associated with increasing radius. Aortic diameter should give us some insight into the stress side of the equation, although only partially so, because blood pressure itself may be overlooked even in guideline statements. ${ }^{2}$

We have little information, however, bearing on the other side of the equation, the material strength of the aorta. We focus on the aortic diameter because that is what we can measure. Material properties must be inferred from our knowledge of underlying genetic conditions such as Marfan syndrome or familial aortic dissection, underlying conditions such as inflammatory arteritis known to cause medial damage, or environmental influences such as cigarette smoking. Indeed, the presence of aneurysmal dilatation itself implies abnormal material properties; it could be

\section{Asymmetric Information, Asymmetric}

\section{Variables}

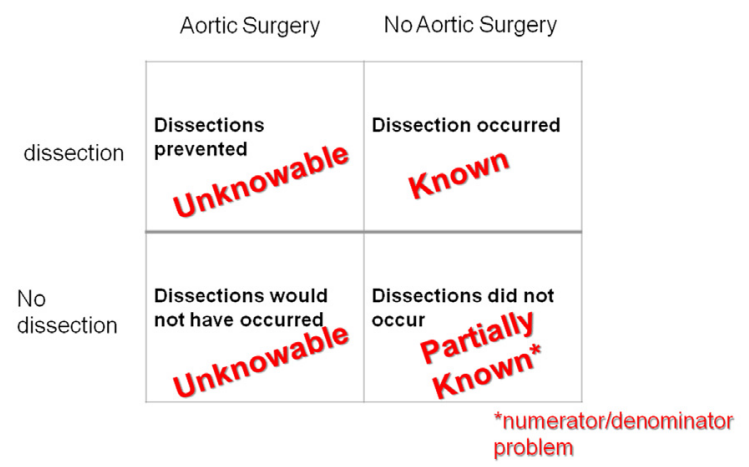

FIGURE 2. This $2 \times 2$ matrix illustrates the data elements required to fully understand the risk trade-off between aortic surgery and aortic dissection. 
argued that this may be as much an explanation for the clinical observation of increased risk of catastrophe with aortic enlargement as Laplace's law. We do not, however, have the tools to measure these properties in an individual patient.

\section{CLINICAL DECISION MAKING}

Regardless of the theoretic limitations of our data, clinical decisions must be made. Early indications, which were that patients undergoing aortic valve replacement (AVR) for BAV had a significant risk of aortic dissection, ${ }^{7}$ were followed by observations of higher numbers of "aortic events," defined as dissection or reoperation for aortic enlargement. ${ }^{8}$ Laboratory data showing histologic, biochemical, and mechanical abnormalities of the aneurysmal aorta associated with BAV have been called on to support a more aggressive approach to the ascending aorta at the time of AVR, and by inference to the aorta even in the presence of a functionally normal valve. Just as diameter is an imperfect predictor of dissection, however, so it turns out is medial degeneration. Roberts and colleagues ${ }^{9}$ have recently reported that, among 69 patients who had acute aortic dissection develop, $82 \%$ had normal or nearly normal numbers of elastic fibers, numbers suggesting that medial abnormality only uncommonly precedes acute dissection. How, then, can we answer the question, "How big and how much?"

In recent years, a number of clinical studies have suggested that the risk of aortic dissection associated with BAV after AVR may not be as high as was previously feared. Golland and associates ${ }^{10}$ followed up 252 patients after AVR for BAV, of whom $15 \%$ had ascending aortic dilatation to a diameter of 4.5 to $4.9 \mathrm{~cm}$. In a mean follow-up of almost 9 years, there were no dissections and only 1 reoperation for ascending aortic aneurysm. McKellar and coworkers ${ }^{11}$ studied the long-term risk of aortic events after AVR for BAV among 1286 patients followed up for a mean of 12 years and observed 13 dissections ( $1 \%$ ). Among patients undergoing AVR with an associated aortic diameter between 4.0 and $5.0 \mathrm{~cm}$, Girdauskas and colleagues ${ }^{12}$ compared the outcomes of 153 patients with BAVs with those of 172 patients with tricuspid aortic valves (TAVs) for a total of 3566 patient-years and observed only 3 dissections, all among the TAV group, with a rate of reoperation that was actually lower among the patients with BAVs $(3 \%$ vs $5 \%)$. Most recently, Lee and associates ${ }^{13}$ observed only 1 dissection among 499 patients with BAVs and aortic diameters of 4.0 to $5.5 \mathrm{~cm}$ followed up for 1590 patient-years. Indeed they observed significant aortic expansion in only 5 patients, all of whom had TAV morphology.

In the absence of AVR, Davies and colleagues ${ }^{14}$ compared outcomes of unrepaired ascending aortic dilatation in patients with BAVs and with TAVs for a mean follow-up of 5 years and found faster growth rates $(0.19 \mathrm{vs} 0.13 \mathrm{~cm} / \mathrm{y})$ but lower rates of aortic dissection, rupture, and death among the patients with BAVs. Among their adult congenital heart defect population, Oliver and coinvestigators ${ }^{15}$ observed a rate of ascending aortic complications of 0.2/100 patient-years for patients with BAV alone, although the presence of associated coarctation increased this risk 7.5-fold. Tzemos and associates $^{16}$ reported an annualized risk of dissection of $0.1 \%$ /patient-year among 642 patients with BAVs followed up for a mean of 9 years, and Michelena and coworkers $^{17}$ reported a rate of dissection of 3.1 events/ 10,000 patient-years among 416 patients followed up for as long as 25 years. A meta-analysis reported on in 2013 by Hardikar and Marwick ${ }^{18}$ led to the conclusion that the risk of acute aortic events in current practice is low.

Given these findings, at a minimum it is hard to support a lower diameter threshold for aortic replacement in the presence of a BAV as compared with a TAV. Indeed, one could argue that the presence of a BAV provides a reassuring explanation for modest aortic enlargement that obviates the need to invoke abnormal material properties. Conversely, moderate degrees of aortic dilatation in the presence of a TAV must be due to abnormal material properties and therefore imply structural weakness. Some support for the notion that, size for size, the aorta associated with a BAV is less prone to dissection can be derived from Eleid and associates' observation ${ }^{19}$ that among patients with known dilatation before dissection the mean diameter was lower for those with a TAV!

And what of the sinus segment and proximal arch? It has been argued by some that the aortic sinus segment should also be routinely replaced the presence of a BAV because of the presumed material weakness of that segment. The clinical observations indicate, however, that the unreplaced sinus segment rarely dilates if left intact at the time of surgery. ${ }^{20}$ This of course presumes that individuals with dilation underwent replacement of the sinus replacement. This is reassuring given that the risk of aortic root replacement, even in experienced hands, is nontrivial. A recent review of data from the Society of Thoracic Surgeons database $^{21}$ demonstrated that the unadjusted operative mortality for aortic elective aortic replacement was 3.4\%, even among high-volume centers.

And what of the arch? Again there are laboratory data to support an argument related to the pattern of the migration of cells of neural crest origin into the arch that bicuspid aortopathy extends into the arch. There are also data from Stanford University indicating that some element of arch dilatation is common in the setting of BAV. ${ }^{22}$ Again, the criterion standard should be the observed clinical behavior. Park and associates ${ }^{23}$ reported on a series of 422 patients with BAVs undergoing replacement of the ascending aorta without intervention on the arch followed up for a median 
of 4 years and for as long as 17 years with no reoperations for arch dilatation.

Taken together, these data suggest that our threshold for replacement of the ascending aorta, arch, and root segments should be no different in the setting of BAV. There is a genuine need for better tools, perhaps focused on the material properties of the aorta, with which to predict the risk of dissection. In the meantime, we must caution against an overly aggressive posture lest we do more harm than good.

\section{References}

1. Edwards WD, Leaf DS, Edwards JE. Dissecting aortic aneurysm associated with congenital bicuspid aortic valve. Circulation. 1978;57:1022-5.

2. Hiratzka LF, Bakris GL, Beckman JA, Bersin RM, Carr VF, Casey DE Jr, et al; American College of Cardiology Foundation/American Heart Association Task Force on Practice Guidelines, American Association for Thoracic Surgery, American College of Radiology, American Stroke Association, Society of Cardiovascular Anesthesiologists, Society for Cardiovascular Angiography and Interventions, Society of Interventional Radiology, Society of Thoracic Surgeons, Society for Vascular Medicine. 2010 ACCF/AHA/AATS/ACR/ASA/ SCA/SCAI/SIR/STS/SVM Guidelines for the diagnosis and management of patients with thoracic aortic disease. A Report of the American College of Cardiology Foundation/American Heart Association Task Force on Practice Guidelines, American Association for Thoracic Surgery, American College of Radiology, American Stroke Association, Society of Cardiovascular Anesthesiologists, Society for Cardiovascular Angiography and Interventions, Society of Interventional Radiology, Society of Thoracic Surgeons, and Society for Vascular Medicine. J Am Coll Cardiol. 2010;55:e27-129. Erratum in: J Am Coll Cardiol. 2013;62:1039-40.

3. Svensson LG, Adams DH, Bonow RO, Kouchoukos NT, Miller DC, O'Gara PT, et al. Aortic valve and ascending aorta guidelines for management and quality measures: executive summary. Ann Thorac Surg. 2013;95:1491-505.

4. Tingling PM, Brydon MJ. Is decision-based evidence making necessarily bad? MIT Sloan Management Review Magazine [Internet]. June 26, 2010. Available at: http://sloanreview.mit.edu/article/is-decision-based-evidence-makingnecessarily-bad/. Accessed May 18, 2014

5. Gilovich T, Griffin D, Kahneman D, eds. Heuristics and biases: the psychology of intuitive judgment. New York: Cambridge University Press; 2002.

6. Pape LA, Tsai TT, Isselbacher EM, Oh JK, O'gara PT, Evangelista A, et al; International Registry of Acute Aortic Dissection (IRAD) Investigators. Aortic diameter $\geq 5.5 \mathrm{~cm}$ is not a good predictor of type A aortic dissection: observations from the International Registry of Acute Aortic Dissection (IRAD). Circulation. 2007;116:1120-7.

7. Russo CF, Mazzetti S, Garatti A, Ribera E, Milazzo A, Bruschi G, et al. Aortic complications after bicuspid aortic valve replacement: long-term results. Ann Thorac Surg. 2002;74:S1773-6; discussion S1792-9.
8. Borger MA, Preston M, Ivanov J, Fedak PW, Davierwala P, Armstrong S, et al Should the ascending aorta be replaced more frequently in patients with bicuspid aortic valve disease? J Thorac Cardiovasc Surg. 2004;128:677-83.

9. Roberts WC, Vowels TJ, Kitchens BL, Ko JM, Filardo G, Henry AC, et al. Aortic medial elastic fiber loss in acute ascending aortic dissection. Am J Cardiol. 2011; 108:1639-44.

10. Goland S, Czer LS, De Robertis MA, Mirocha J, Kass RM, Fontana GP, et al Risk factors associated with reoperation and mortality in 252 patients after aortic valve replacement for congenitally bicuspid aortic valve disease. Ann Thorac Surg. 2007;83:931-7.

11. McKellar SH, Michelena HI, Li Z, Schaff HV, Sundt TM 3rd. Long-term risk of aortic events following aortic valve replacement in patients with bicuspid aortic valves. Am J Cardiol. 2010;106:1626-33.

12. Girdauskas E, Disha K, Borger MA, Kuntze T. Long-term prognosis of ascending aortic aneurysm after aortic valve replacement for bicuspid versus tricuspid aortic valve stenosis. J Thorac Cardiovasc Surg. 2014;147:276-82.

13. Lee SH, Kim JB, Kim DH, Jung SH, Choo SJ, Chung CH, et al. Management of dilated ascending aorta during aortic valve replacement: valve replacement alone versus aorta wrapping versus aorta replacement. J Thorac Cardiovasc Surg. 2013;146:802-9.

14. Davies RR, Kaple RK, Mandapati D, Gallo A, Botta DM Jr, Elefteriades JA, et al Natural history of ascending aortic aneurysms in the setting of an unreplaced bicuspid aortic valve. Ann Thorac Surg. 2007;83:1338-44.

15. Oliver JM, Alonso-Gonzalez R, Gonzalez AE, Gallego P, Sanchez-Recalde A Cuesta E, et al. Risk of aortic root or ascending aorta complications in patients with bicuspid aortic valve with and without coarctation of the aorta. Am J Cardiol. 2009;104:1001-6.

16. Tzemos N, Therrien J, Yip J, Thanassoulis G, Tremblay S, Jamorski MT, et al Outcomes in adults with bicuspid aortic valves. JAMA. 2008;300:1317-25.

17. Michelena HI, Khanna AD, Mahoney D, Margaryan E, Topilsky Y, Suri RM, et al. Incidence of aortic complications in patients with bicuspid aortic valves. JAMA. 2011;306:1104-12.

18. Hardikar AA, Marwick TH. Surgical thresholds for bicuspid aortic valve associated aortopathy. JACC Cardiovasc Imaging. 2013;6:1311-20.

19. Eleid MF, Forde I, Edwards WD, Maleszewski JJ, Suri RM, Schaff HV, et al. Type A aortic dissection in patients with bicuspid aortic valves: clinical and pathological comparison with tricuspid aortic valves. Heart. 2013;99:1668-74.

20. Park CB, Greason KL, Suri RM, Michelena HI, Schaff HV, Sundt TM III. Fate of nonreplaced sinuses of Valsalva in bicuspid aortic valve disease. J Thorac Cardiovasc Surg. 2011;142:278-84.

21. Hughes GC, Zhao Y, Rankin JS, Scarborough JE, O'Brien S, Bavaria JE, et al Effects of institutional volumes on operative outcomes for aortic root replacement in North America. J Thorac Cardiovasc Surg. 2013;145:166-70.

22. Fazel SS, Mallidi HR, Lee RS, Sheehan MP, Liang D, Fleischman D, et al. The aortopathy of bicuspid aortic valve disease has distinctive patterns and usually involves the transverse aortic arch. J Thorac Cardiovasc Surg. 2008;135:901-7, 907.e1-2.

23. Park CB, Greason KL, Suri RM, Michelena HI, Schaff HV, Sundt TM III. Should the proximal arch be routinely replaced in patients with bicuspid aortic valve disease and ascending aortic aneurysm? J Thorac Cardiovasc Surg. 2011;142: 602-7. 